\title{
Wet hydrogen peroxide oxidation of synthetic pharmaceutical wastewater as a pretreatment method
}

\author{
ZENG Xua , LIU Jun and ZHAO Jianfu \\ State Key Laboratory of Pollution Control and Resources Reuse \\ College of Environmental Science and Engineering, Tongji University, Shanghai, China \\ azengxu@tongji.edu.cn
}

\begin{abstract}
Keywords: Wet hydrogen peroxide oxidation; Synthetic pharmaceutical wastewater; Pretreatment method.

Abstract. Wet hydrogen peroxide oxidation of synthetic pharmaceutical wastewater as a pretreatment method was investigated. The reaction parameters, such as reaction temperature and time, $\mathrm{pH}$ and the additional amount of $\mathrm{H}_{2} \mathrm{O}_{2}$, were examined using a batch reactor with COD removal rate as a standard for assessing. Results showed that the highest removal rate of COD was obtained at $240{ }^{\circ} \mathrm{C}$ for $60 \mathrm{~min}$ with the $\mathrm{H}_{2} \mathrm{O}_{2}$ additional amount $2 \mathrm{~mL}$. HPLC analysis results showed that the pollutants in synthetic pharmaceutical wastewater were converted into small molecule carboxylic acids after the reaction, therefore the biodegradability of wastewater was enhanced. Wet hydrogen peroxide oxidation treatment displayed effectively for the pretreatment of synthetic pharmaceutical wastewater.
\end{abstract}

\section{Introduction}

Due to the rapid increase of pharmaceutical compounds production in the past few decades, large amounts of pharmaceutical wastewater were generated. Normally, conventional biological method is considered as the most economical and ideal choice of wastewater treatment. However, it is not very suitable for the treatment of pharmaceutical wastewater, because the pollutants in the pharmaceutical wastewater are always nonbiodegradable and persistent to the biological systems, especially including some heavy metal ion, which make pharmaceutical wastewater as one of the most toxic industrial wastewaters ${ }^{[1-3]}$.

Recently, extensive researches have been performed focused on developing new approaches for the treatment of pharmaceutical wastewater. Advanced oxidation processes (AOPs) are considered as one of the most effective treatment technologies for the decomposition of bioresistant organic contaminants ${ }^{[4,5]}$. In these AOPs treatment methods, the generation of sufficient reactive species such as hydroxyl radicals $(\cdot \mathrm{OH})$ leads to the effective decomposition of organic pollutants ${ }^{[6,7]}$. Wet oxidation has shown its effectiveness and promising property with several industrial effluents, including benzene, biphenyls, amines and pyridine ${ }^{[8-11]}$.This process performed the liquid-phase oxidation of toxic or poorly biodegradable compounds under high temperature $\left(150 \sim 350{ }^{\circ} \mathrm{C}\right)$ and pressure (2.0 15.0 MPa) conditions, using a gaseous source of oxygen or air. During this process, the pollutants were oxidized completely ${ }^{[12,13]}$. It should be noted that, this process can be considered as a green and environmental-friendly technology since it emits no harmful materials or secondary pollution to the environment ${ }^{[14,15]}$.

Wet Hydrogen Peroxide Oxidation (WHPO) has been developed in order to increase the efficiency of conventional wet oxidation systems by using $\mathrm{H}_{2} \mathrm{O}_{2}$ as an oxidation agent, which can product large amount of hydroxyl radicals ${ }^{[16,17]}$. WHPO has demonstrated high efficiency for the treatment of agro-food and industrial effluents as well as sewage sludges ${ }^{[18]}$, although it exists some commen drawbacks of wet oxidation, such as the intensive energy requirements and hydrogen peroxide consumptions. Unlike wet oxidation with air or oxygen gas, in which the degradation rate is strongly limited by the mass transfer of molecular oxygen from the gas to the liquid phase, WHPO takes advantage of employing hydrogen peroxide as liquid oxidant which avoids gas-liquid mass transfer restrictions and consequently increased the efficiency enormously. 
In this study, wet hydrogen peroxide oxidation was applied for the pretreatment of synthetic pharmaceutical wastewater. The reaction parameters, such as reaction temperature and time, $\mathrm{pH}$ and the additional amount of $\mathrm{H}_{2} \mathrm{O}_{2}$, were examined using a batch reactor with COD removal rate as a standard for assessing.

\section{Materials and methods}

Materials. The raw synthetic pharmaceutical wastewater was collected in a synthetic pharmacetutical factory, located in the east of China. The characters of the raw wastewater is as follows: COD 15 000 16 $000 \mathrm{mg} / \mathrm{L}, \mathrm{pH} 8.0 \sim 9.0$. The raw wastewater was adopted without any treatment. The materials used in this experiments, such as hydrogen peroxide (solution with the concentration 30\%), $\mathrm{NaOH}$, were purchased from Sinopharm Chemical Reagent (Shanghai, China). All the chemicals were used as received without further purification.

Experimental procedure. All experiments were conducted in a SUS316 reactor with an internal volume of $100 \mathrm{~mL}$ which was purchased from Anhui Kemi Machinery Technology Co. Ltd, China. The typical procedure is the following: desired amounts of synthetic pharmaceutical wastewater and hydrogen peroxide were put into the reactor, which was then increased the temperature to $180 \sim 240{ }^{\circ} \mathrm{C}$. After the desired reaction temperature was achieved, the reaction time was started. Once desired reaction time elapsed, the reactor was removed from the oven and allowed to cool to room temperature. Generally, approximately $20 \mathrm{~min}$ was required to heat the liquid in the reactors to their reaction temperature, and the pressure in the reactor corresponded to the saturated vapor pressure of water at the liquid temperature.

Analysis method. $\mathrm{pH}$ was measured by $\mathrm{pH}$ meter (pH-201, Hanna Corporation, Italy), and $\mathrm{BOD}_{5}$ was analyzed by the respirometric method (Hach heating system, Hach Corporation, USA). Since the composition of synthetic pharmaceutical wastewater was very complicated, COD was used to assess the treatment efficiency in this study, which was measured by the potassium dichromate oxidation method (Hach Heating System, Hach Corporation, USA). The liquid samples were collected, diluted, and analyzed using a high-performance liquid chromatography instrument (HPLC, Agilent 1200LC) equipped with two RSpak KC-811 (SHODEX) columns.

\section{Results and discussion}

Effect of reaction temperature on the COD removal rate. The effect of reaction temperature (in the range of $180 \sim 240{ }^{\circ} \mathrm{C}$ ) on the wet hydrogen peroxide oxidation of selected pharmaceutical wastewater at residence time of $60 \mathrm{~min}$ with additional amount $2 \mathrm{~mL} \mathrm{of} \mathrm{H}_{2} \mathrm{O}_{2}$ is investigated. The results can be seen in Fig. 1. As shown in Fig. 1, as expected, the oxidation reaction in terms of COD degradation accelerates when increasing the temperature, considering the Arrhenius law in the kinetic regime. While the COD removal rate is relative low at the reaction temperature $180{ }^{\circ} \mathrm{C}$, it means that this reaction needs high temperature to acquire satisfied COD removal rate. Theoretically, COD removal rate can be very high at high reaction temperature with enough oxidation agent. However, the COD removal rate is still not $100 \%$ even at $240^{\circ} \mathrm{C}$ for $60 \mathrm{~min}$, it is probably because the incompletely degradation of COD. It has been reported that carboxylic acids with small molecule amount, such as formic acid or acetic acid, are not easy to be oxidized under hydrothermal conditions. Therefore, the highest COD removal rate, $87 \%$, was obtained at $240{ }^{\circ} \mathrm{C}$ for $60 \mathrm{~min}$ with additional amount $2 \mathrm{~mL}$ of $\mathrm{H}_{2} \mathrm{O}_{2}$. The COD removal rate increased significantly with the increase of reaction temperature from $180{ }^{\circ} \mathrm{C}$ to $240{ }^{\circ} \mathrm{C}$, however the increase of COD removal rate is not so high from $240{ }^{\circ} \mathrm{C}$ to $260{ }^{\circ} \mathrm{C}$. In addition, the obtained data indicate that among the reaction by-products formed during the COD degradation, some of them are non-oxidizable and remain in the final solution under the employed conditions, because a plateau is observed with the reaction temperature from $240{ }^{\circ} \mathrm{C}$ to $260{ }^{\circ} \mathrm{C}$. Similar dependencies between the COD removal rate and the employed temperature were found in reported WHPO process. Considering the reaction temperatures, $240{ }^{\circ} \mathrm{C}$, might be considered 
satisfactory for the COD removal because energy and efficiency reason. Therefore, reaction temperature, $240{ }^{\circ} \mathrm{C}$, was adopted in the following runs when other operating parameters were discussed.

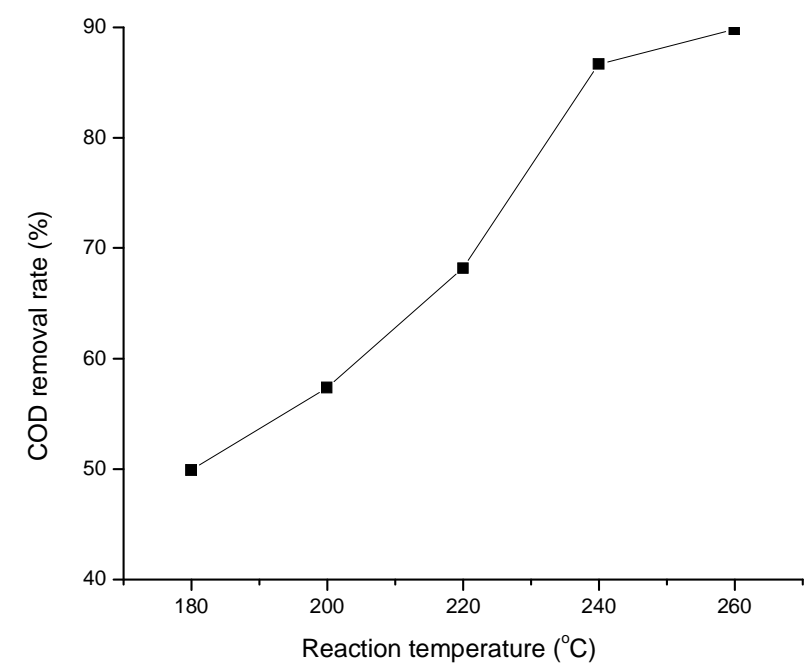

Fig. 1. Effect of temperature on the COD removal rate (reaction time $60 \mathrm{~min}, \mathrm{H}_{2} \mathrm{O}_{2}$ amount $2 \mathrm{~mL}$ ).

Effect of $\mathrm{H}_{2} \mathrm{O}_{2}$ additional amount on the COD removal rate. The initial $\mathrm{H}_{2} \mathrm{O}_{2}$ additional amount was varied from 1.0 to $2.5 \mathrm{~mL}$ while maintaining the other parameters constant. The results were shown in Fig. 2. It can be seen in Fig. 2 that $\mathrm{H}_{2} \mathrm{O}_{2}$ plays an important role on the COD removal. This behavior was also expected because the increase of the oxidant concentration usually leads to an increase in the oxidation rate. However, the COD removal rate changed not so much with the increase of $\mathrm{H}_{2} \mathrm{O}_{2}$ additional amount from 2.0 to $2.5 \mathrm{~mL}$. It should be noted that, wet hydrogen peroxide oxidation was used as a pretreatment method in this study, the complete oxidation of COD was not the final target. Thus, in the following runs, $\mathrm{H}_{2} \mathrm{O}_{2}$ additional amount, $2 \mathrm{~mL}$, was used.

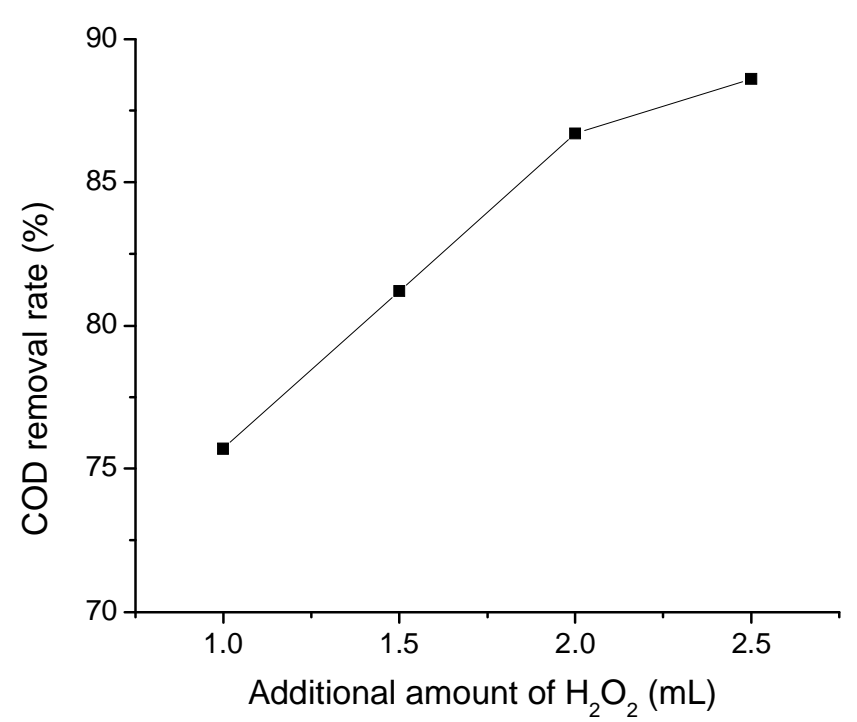

Fig. 2. Effect of additional amount of $\mathrm{H}_{2} \mathrm{O}_{2}$ on the $\mathrm{COD}$ removal rate $\left(240{ }^{\circ} \mathrm{C}, 60 \mathrm{~min}\right)$.

Effect of reaction time on the COD removal rate. Fig. 3 shows the effect of reaction time on the COD removal rate at $240{ }^{\circ} \mathrm{C}$ with $\mathrm{H}_{2} \mathrm{O}_{2}$ amount $2 \mathrm{~mL}$. The reaction time was changed from 15 min to $60 \mathrm{~min}$. The results showed that the COD removal rate is very high even with the reaction time $15 \mathrm{~min}$, which means that the wet hydrogen peroxide oxidation process took place quickly. This behavior was expected because the free radical reaction was very fast. Extensive studies reported that the hydrogen 
peroxide oxidation process is free radical reaction. The COD removal rate increased gradually with the increase of reaction time from $15 \mathrm{~min}$ to $60 \mathrm{~min}$.



Fig. 3. Effect of the reaction time on the COD removal rate $\left(240{ }^{\circ} \mathrm{C}, \mathrm{H}_{2} \mathrm{O}_{2}\right.$ amount $\left.2 \mathrm{~mL}\right)$.

Effect of pharmaceutical wastewater concentration on the COD removal rate. To investigate the effect of pharmaceutical wastewater concentration on the COD removal rate, experiments were performed with pharmaceutical wastewater COD 5000 6000 mg/L. Results can be seen in Fig. 4. As shown in Fig. 4, the increase trend of reaction temperature is similar with the pharmaceutical wastewater COD 15000 16000 $\mathrm{mg} / \mathrm{L}$. However, the COD removal rate was not so high, about $50 \% \sim 60 \%$. The reason may be that the carboxylic acids with small molecule amount produced in the reaction, such as formic acid or acetic acid, are not easy to be oxidized under hydrothermal conditions. Therefore, the COD removal rate was not very high with low pharmaceutical wastewater concentration. It illustrated that the wet hydrogen peroxide oxidation method should be used as a pretreatment method for the pharmaceutical wastewater with high COD value.

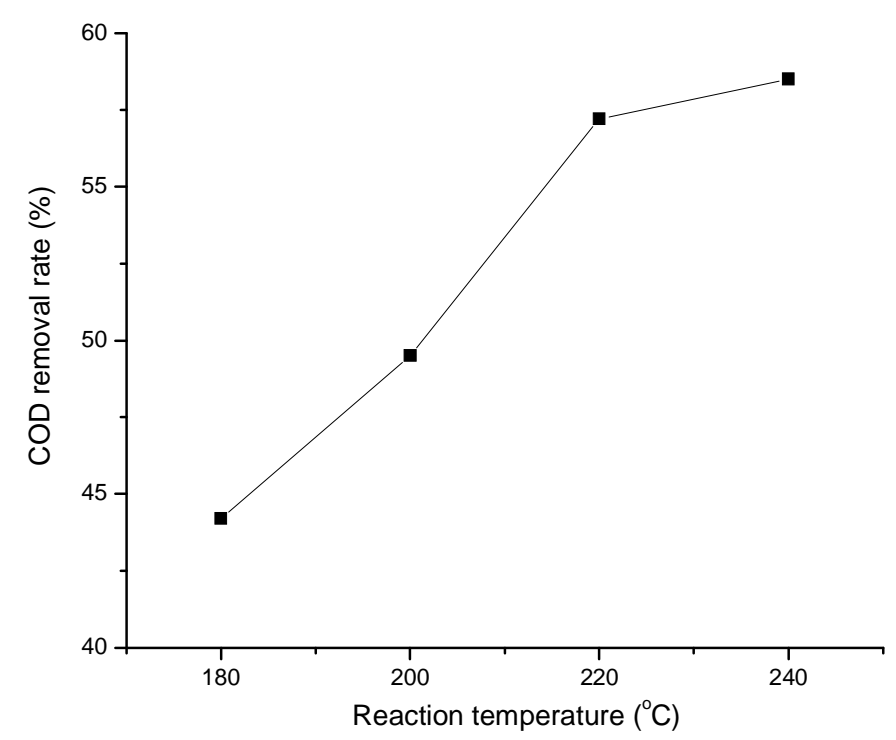

Fig. 4. Effect of temperature on the COD removal rate with low concentration of pollutants (reaction time $60 \mathrm{~min}, \mathrm{H}_{2} \mathrm{O}_{2}$ amount $2 \mathrm{~mL}$ ).

BOD and HPLC analysis of the liquid samples before and after the reaction. The BOD analysis of the liquid samples before and after the reaction showed the increase of B/C value after wet hydrogen peroxide oxidation, which means that wet hydrogen peroxide oxidation is an effective 
method for the treatment of non-biodegradable wastewater to enhance the biodegradable property. HPLC analysis of the of the liquid samples before and after the reaction showed that the significant decrease of pollutants with large molecule amount, considering the removal of carboxylic acids with small molecule amount.

\section{Conclusions}

In this study, wet hydrogen peroxide oxidation of synthetic pharmaceutical wastewater was investigated. The reaction parameters, such as reaction temperature and time, $\mathrm{pH}$ and the additional amount of $\mathrm{H}_{2} \mathrm{O}_{2}$, were examined using a batch reactor with COD removal rate as a standard for assessing. Results showed that the highest removal rate of COD was obtained at $240{ }^{\circ} \mathrm{C}$ for 60 min with the $\mathrm{H}_{2} \mathrm{O}_{2}$ additional amount $2 \mathrm{~mL}$. HPLC analysis results showed that the pollutants in synthetic pharmaceutical wastewater were converted into small molecule carboxylic acids after the reaction, therefore the biodegradability of wastewater was enhanced. Wet hydrogen peroxide oxidation treatment displayed effectively for the pretreatment of synthetic pharmaceutical wastewater.

\section{References}

[1] M. Huerta-Fontela, M.T. Galceran, F. Ventura. Occurrence and removal of pharmaceuticals and hormones through drinking water treatment. Water Research, 2011, 45: 1432-1442.

[2] A.Y.-C. Lin, T.-H. Yu, S.K. Lateef. Removal of pharmaceuticals in secondary wastewater treatment processes in Taiwan. J. Hazardous Materials, 2009, 167: 1163-1169.

[3] M. Jelic, A. Gros. Occurrence, partition and removal of pharmaceuticals in sewage water and sludge during wastewater treatment. Water Research, 2011, 45: 1165-1176.

[4] H. Yu, E. Nie, J. Xu. Degradation of diclofenac by advanced oxidation and reduction processes: kinetic studies, degradation pathways and toxicity assessments. Water Res., 2013, 47: 1909-1918.

[5] C. F. Bustillo-Lecompte, M. Mehrvar. Cost-effectiveness analysis of TOC removal from slaughterhouse wastewater using combined anaerobiceaerobic and $\mathrm{UV} / \mathrm{H}_{2} \mathrm{O}_{2}$ processes. $J$. Environ. Manage., 2014, 134: 145-152.

[6] S. Contreras, M. Rodriguez, F. A. Momani. Contribution of the ozonation pre-treatment to the biodegradation of aqueous solutions of 2,4-dichlorophenol. Water Res., 2003, 37: 3164-3171.

[7] S. Ghafoori, M. Mehrvar, P. Chan. Photo assisted Fenton-like degradation of aqueous poly (acrylic acid): from mechanistic kinetic model to CFD modeling. Chem. Eng. Res. Des., 2013, 91: 2617-2629.

[8] P. E. Savage, S. Gopalan, T. I. Mizan, C. J. Martino, E. E. Brock. Reactions at supercritical conditions: applications and fundamentals. AIChE J., 1995, 41: 1723-1778.

[9] R. Weber, Sh. Yoshida, K. Miva. PCB destruction in subcritical and supercritical water evaluation of PCDF formation and initial steps of degradation mechanisms. Environ. Sci. Tech., 2002, 36: 1839-1844.

[10] B. Veriansyah, J. D. Kim, J. C. Lee. Destruction of chemical agent in a supercritical water oxidation bench-scale reactor. J. Hazardous Materials, 2007, 147: 8-14.

[11] N. Crain, S. Tebbal, L. Li, E.F. Gloyna. Kinetics and reaction pathways of pyridine oxidation in supercritical water. Ind. Eng. Chem. Res., 1993, 32: 2259-2268.

[12] P. Kritzer, E. Dinjus. An assessment of supercritical water oxidation: existing problems, possible solutions and newreactorconcepts. Chemical Engineering J., 2001, 83: 207-214.

[13] M. Hodes, P.A. Marrone, G.T. Hong, K.A. Smith, J.W. Tester. Salt precipitation and scale control in supercritical water oxidation-Part A: fundamentals andresearch. J. Supercritical Fluids, 2004, 29: 265-288.

[14] B. Veriansyah, T.-J. Park, J.S. Lim, Y.-W. Lee. Supercritical water oxidation of wastewater from LCD manufacturing process: kinetic and formation of chromium oxide nanoparticles. $J$. Supercritical Fluids, 2005, 34: 51-61. 
[15] Z. Fang, S. K. Xu, R. L. Smith Jr., K. Arai, J.A. Kozinski. Destruction of deca-chlorobiphenyl in supercritical water under oxidizing conditions with and without $\mathrm{Na}_{2} \mathrm{CO}_{3}$. J. Supercritical Fluids, 2005, 33: 247-258.

[16] S. Caudo, G. Centi, C. Genovese. Copper and iron-pillared clay catalysts for the WHPCO of model and real wastewater streams from olive oil milling production. Appl. Catal. B: Environ., 2007, 70: 437-446.

[17] P. Bautista, , A. F. Mohedano, J. A. Casas. An overview of the application of Fenton oxidation to industrial wastewaters treatment. J. Chem. Technol. Biotechnol., 2008, 83: 1323-1338.

[18] S. K. Bhargava, J. Tardio, J. Prasad. Wet oxidation and catalytic wet oxidation. Ind. Eng. Chem. Res., 2006, 45(4): 1221-1258. 